\title{
Reportagem \\ A força propulsora do diálogo social
}

Lideranças sindicais, empresariais, sociais, além de intelectuais, acadêmicos e representantes de variados setores, têm trabalhado desde 2003 em uma proposta inovadora: pensar o Brasil que se deseja e, a partir daí, apresentar ao presidente da República indicações do rumo para tornar o País socialmente justo e economicamente sustentável.

Essa é a tarefa do Conselho de D esenvolvimento Econômico e Social (CDES), composto por 90 pessoas da sociedade civil e 13 ministros, que se constitui em espaço de diálogo no qual a diversidade dos atores sociais, mais do que revelar a heterogeneidade da população de um país continental, possibilita ampliar os pontos de vista e os argumentos sobre temas da agenda nacional, enriquecendo o debate e qualificando as sugestões para um projeto de desenvolvimento de longo prazo.

Com o surgimento do CDES, a discussão de grandes temas deixou de ser uma conversa de pequenos grupos, com acesso ao presidente, para ser um exercício pleno de representação dos diversos grupos, a maior parte dos quais não tinha canal para seus pleitos e demandas ao governo. "Não há mais vanguarda. 0 acesso e o fluxo de informação tornaram-se produtos de todos. Acabou a demanda de balcão, a visão tradicional

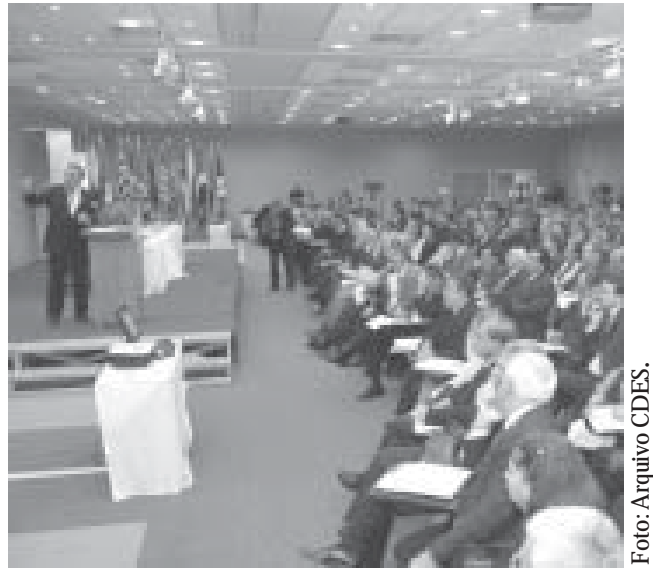

CDES, espaço em que se discute a reforma tributária

de um Conselho, que cooptava as pessoas para a defesa de determinadas idéias. Agora o diálogo é sem rupturas. É um modo de trazer governança, criar consenso, estabelecer espaço de convergência", diz a responsável pela Secretaria do Conselho de D esenvolvimento Econômico e Social (Sedes), Esther Bemerguy Albuquerque.

\section{Agenda}

0 processo da construção de consensos passa hoje pela Agenda Nacional de D esenvolvimento (AND), cuja versão preliminar foi elaborada por um Grupo de Trabalho (GT) integrado por, aproximadamente, 50 conselheiros. Tal versão, apresentada na reunião plenária de maio de 
2005, resultou de estudos, debates, seminários realizados por especialistas sobre os principais problemas nacionais e elementos para uma visão de futuro do País.

Isso resultou na escolha de seis "âmbitos problemáticos", que incluem: 1) a extrema desigualdade social, já considerados os diferenciais de gênero e raça; 2) a falta de dinâmica da economia para promover a incorporação do mercado interno potencial e a competição internacional; 3) a degradação dainfra-estrutura logística; 4) a inexistência de um eficaz sistema nacional público/ privado de financiamento do investimento e a irracionalidade da estrutura tributária; 5) a insegurança pública e cidadã, bem como uma justiça pouco democrática; e 6) a baixa capacidade operativa do Estado.

D urante um ano e meio, a Agenda Nacional de Desenvolvimento foi cuidadosamente construída, possibilitando a elaboração pelo CD ES de documento que elegeu 27 estratégias essenciais ao crescimento do País, com eqüidade, e a seis objetivos, decorrentes dos maiores problemas identificados. Todos os conselheiros participaram da etapa de ajuste do documento, fundamental para a aprovação por consenso da versão final, na plenária de agosto de 2005.

A Agenda Nacional de Desenvolvimento compreende, assim, uma perspectiva permanente de visão de futuro do País sob a ótica dos conselheiros, contribuindo não apenas com a descrição dos problemas que devem ser enfrentados, mas com sugestões para objetivos a serem alcançados e as diretrizes estratégicas para nortear as ações do governo e da sociedade. Essa é uma importante novidade no cenário brasileiro por se tratar de uma construção coletiva, que envolve múltiplos segmentos da sociedade - com eixo na superação das desigualdades - e aposta na eqüidade como critério para alcançar esse propósito.

\section{Observatónio}

A criação do Observatório da Eqüidade, em março de 2006, surgiu da necessidade de o CDES ter instrumentos para monitorar o processo de desenvolvimento nacional, uma vez que não existia, até então, uma metodologia definida para isso. A equipe técnica é formada pelo IPEA, IBG E, D ieese e pela Secretaria do Conselho de Desenvolvimento Econômico e Social. A gestão do Observatório está a cargo do Conselho Diretor, constituído por 12 conselheiros do CDES.

"No começo, o diálogo interinstitucional era difícil, já que não havia precedente. As entidades nunca tinham construído nada juntas. Em 2007, entretanto, a soma dos esforços fortaleceu a integração", explica a secretária Esther Bemerguy Albuquerque.

0 Observatório tem a finalidade de acompanhar o enfrentamento do problema e apoiar a proposição de políticas públicas e ações sociais capazes efetivamente de promover maior eqüidade. É responsável por produzir informação e conhecimento, de modo a subsidiar o CDES e propor estratégias e instrumentos para o desenvolvimento do País. Sua produção deve, ainda, ampliar o conhecimento e a capacidade de a sociedade debater, avaliar e cobrar resultados das políticas governamentais e das ações dos demais atores sociais.

Para o conselheiro e integrante da Executiva Nacional da Associação Brasileira de Organizações Não-Governamentais (Abong), José Antonio Moroni, o Observatório é um instrumento do Conselho que, em sua formatação, não se limita à atuação interna. "Tanto éque existe 
a Rede de 0 bservação. Ela envolve organizações que não integram o CD ES. Há um convite permanentemente aberto para que outras organizações e pesquisadores venham para a Rede, de modo a tornar 0 Observatório um amplo instrumento de debate da sociedade", diz.

0 primeiro problema trabalhado pelo Observatório da Eqüidade foi a desigualdade no acesso e na qualidade da educação, tema imprescindível porque não se imagina um país na rota do desenvolvimento sem contemplar a qualidade e a universalização do ensino. A o O bservatório caberia apontar as causas dessa situação de desigualdade e definir indicadores de acompanhamento do desempenho das ações para elevar a escolaridade da população em todo o território nacional.

Missão cumprida. Em pouco menos de um ano, um Grupo de Trabalho construiu a metodologia, democratizou 0 modelo explicativo da Educação com toda a rede social ligada aos conselheiros, e realizou a primeira rodada de produção de indicadores. $O$ diretor técnico do D ieese e conselheiro do CDES, Clemente Ganz Lúcio, fala da importância desse trabalho: "A partir dos desafios e problemas que 0 Conselho seleciona, o Observatório organiza uma abordagem técnica que proporcione à diversidade de opiniões um diferencial comum para a discussão política". Ele explica que, ao apontar causas e selecionar indicadores, o Observatório possibilita maior objetividade e agilidade ao debate. "Daqui a um ano, quando o Conselho voltar a analisar a Educação, utilizará as informações geradas pelo O bservatório e terá condições de ver a evolução histórica, saber como caminhou a universalização, se melhorou a qualidade do ensino", comenta.

Mais dois temas foram indicados e possuem grupos de trabalho constituídos.
Um para avaliar a questão da reforma tributária e, outro, para analisar a bioenergia.

\section{Reforma}

Percebida como eixo estratégico para o desenvolvimento com eqüidade, a reforma tributária tem sido um dos temas mais importantes na pauta de discussões e deliberações do CDES, desde 2003. São daquele ano as primeiras recomendações do Conselho ao projeto de lei que seria encaminhado ao Congresso Nacional, entre as quais se destacam a adoção de imposto estadual unificado com legislação e normatização uniformes, reduzindo e eliminando as 27 legislações diferentes; a desoneração da folha de pagamento; e a incidência não-cumulativa das contribuições.

Ainda em 2003, foi assinado pelo Conselho o "Acordo sobre a Carga Tributária", no qual era destacado o compromisso, na elaboração da Proposta de Emenda Constitucional (PEC), de não elevar a carga tributária.

A Agenda Nacional de Desenvolvimento, aprovada em 2005, também abordou 0 assunto. Entre seus objetivos, havia 0 de ".. construir uma estrutura tributária simplificada e racional, com tributos de qualidade, progressiva e estimuladora da produção e do emprego".

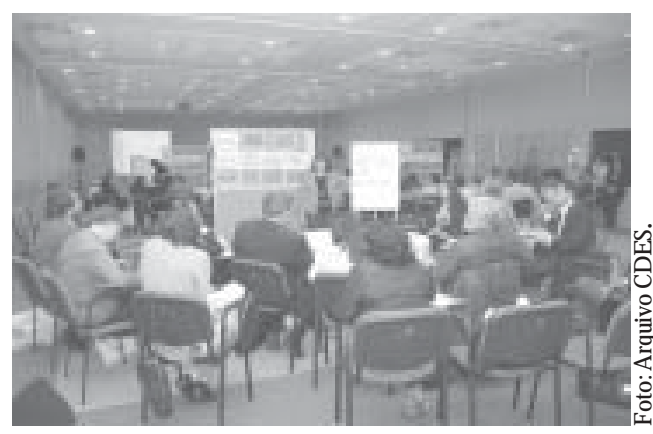

O ficina realizada em 2008 debate os indicadores de qualidade do sistema tributário 
Em 2006, quando o CDES elaborou diretrizes, tendo como horizonte de longo prazo 0 ano de 2022, entre os 24 enunciados consensuais, envolvendo diversos temas, destacava-se a necessidade da reforma tributária. Naquele documento, os conselheiros pactuaram a necessidade de redução da carga fiscal para um patamar em torno de $33 \%$ no prazo máximo de cinco anos, bem como de garantia das condições necessárias para que os estados pratiquem uma política tributária que respeite os princípios de neutralidade e justiça social. "Para isso, a reforma tributária deve isentar de ICMS os alimentos e remédios e implementar o princípio do destino para o ICMS por meio da eliminação gradual do imposto interestadual, como forma de acabar com a guerra fiscal e as fraudes", relata o documento.

Em 2007, com a conjuntura econômica e política do País mostrando-se favorável ao debate da reforma tributária, o CDES formou um novo grupo de trabalho para apoiar o tema. $\mathrm{Na}$ atuação do O bservatório, estava a possibilidade de aprofundar 0 assunto e definir indicadores que ajudem a acompanhar os efeitos das mudanças propostas. As contribuições do CDES estão reunidas no documento "Reforma tributária: um eixo estratégico para o desenvolvimento com eqüidade", divulgado no final de 2007, após seis reuniões com dirigentes do Ministério da Fazenda para discutir e esclarecer pontos de convergência e de divergência entre as propostas do Executivo e as do Conselho.

\section{Pluralidade}

O CDES entende como urgente e necessária a reforma por considerar 0 modelo atual um desestímulo aos investimentos produtivos, mas não concorda integralmente com a proposta do governo. Para o Conselho, a reforma deve ir além da simplificação de impostos indiretos: "Os impostos indiretos, cobrados sobre o consumo - de modo uniforme de ricos e pobres - constituem a maior parcela dos impostos arrecadados, fazendo com que 0 ônus da contribuição recaia sobre os mais pobres. Promover uma distribuição social mais justa da carga tributária deve ser 0 objeto da reforma".

Clemente Ganz Lúcio, que compõe a bancada dos trabalhadores no Conselho, diz que o governo tem discutido a reforma, mas o O bservatório não quer se restringir a ela. Pretende analisar o sistema tributário e criar demandas para uma segunda geração de reformas, que visem a atacar o problema da justiça e da eqüidade.

"O Grupo de Trabalho já analisou a reforma apresentada pelo governo e concluiu que ela melhora o que existe hoje porque simplifica tributos e enfrenta 0 problema da guerra fiscal. Entretanto, é uma proposta que apresenta muitas falhas, ao não tratar da regressividade do sistema, da desvinculação de receitas que até então tinham destino certo...", diz o diretor técnico do Dieese.

$O$ representante da Abong no CD ES, José Antonio Moroni, também se preocupa com a desvinculação das receitas. Ele ressalta que "o principal nó dessa reforma está relacionado ao orçamento da seguridade ou contas vinculadas às políticas sociais: seguridade, saúde, previdência, assistência, educação e trabalho, FAT, PIS". Para ele, está havendo um desmonte do que foi conquistado como proteção social na Constituição de 1988. "A proteção estará assegurada porque é um direito, mas não haverá recurso para garantir o financiamento das ações associadas a essas políticas", explica, ressaltando que a 
observação estará presente na construção dos indicadores, para que se possa tentar evitar perdas à sociedade.

Moroni lembra ainda que a primeira proposta de reforma do presidente Lula, em 2003, tinha como princípio a justiça tributária: quem mais tem, mais contribui; quem menos tem, menos contribui. " $\mathrm{E}$ exatamente quem menos contribui é que deve ter mais acesso ao serviço público o inverso do que ocorre hoje", comenta.

$\mathrm{Nem}$ todos concordam com essa definição de justiça tributária. 0 empresário Antoninho Trevisan critica a idéia do imposto progressivo e diz que o mundo todo caminhou de modo diferente. "Cada país buscou simplificar a forma de agir, ou seja, buscou ter menos alíquotas para fazer a justiça fiscal na aplicação. Eu, inclusive, cobro a tendência de haver uma alíquota única em todo o mundo. Arrecada-se um percentual igual e aplica-se de forma diferenciada: quem ganha muito, recebe $0,5 \%$; quem ganha pouco, recebe $95,5 \% "$.

Para o empresário do ramo contábil, que trabalha há quase quatro décadas com o tema, é inócua e frustrante a tentativa de arrecadar e distribuir a renda, ao mesmo tempo. Ele defende um sistema tributário simples, fala da importância de uma fiscalização atuante, mas, especialmente, de uma rigorosa aplicação dos recursos - nas palavras de Trevisan, é necessário um olhar muito mais claro sobre como dividimos 0 que é arrecadado.

"O tributo no Brasil sempre foi gerado em um ambiente fiscal deficitário e, assim, não se cuidou da justiça tributária e fiscal. Agora podemos pensar nisso porque 0 Brasil está muito bem, do ponto de vista econômico. Mas entendemos queé preciso discutir o sistema tributário (receita) e 0 sistema fiscal (receita e despesa). Só assim, pensando na alocação do gasto, é que podemos suprir de maneira eficaz as deficiências na distribuição de renda", diz 0 empresário.

Todas essas questões foram analisadas no seminário Reforma Tributária, realizado no dia 15 de maio, em Brasília, que reuniu representantes do Executivo, do Legislativo, do empresariado, das organizações sociais e do meio sindical. Entre os presentes, o ministro das Relações

\section{Proposta do Executivo}

O governo apresentou este ano, ao Congresso Nacional, a PEC 233/ 08, que traz suas proposições para a reforma tributária. Entre as mudanças previstas para corrigir distorções, destacam-se a simplificação na cobrança do Imposto sobre Circulação de Mercadorias ePrestação de Serviços (ICMS), que passaria a ter alíquotas unificadas nacionalmente; a eliminação da guerra fiscal, a partir da transição, ao longo de oito anos, da cobrança na origem para a cobrança no destino; a desoneração da folha salarial, com a extinção da contribuição social do Salário-Educação e com a redução de 20\% para 14\% da contribuição dos empregadores para a Previdência.

O Executivo propõe aindaa extinção dos tributosvinculados ao financiamento da seguridade social (Cofins, CSLL), ao Fundo de Amparo ao Trabalhador (FAT) e ao BNDES, e à infraestrutura de transportes e outras finalidades (Cide-Combustíveis).

Está prevista também a criação do Fundo de Equalização de Receitas (FER), cujos recursos seriam utilizados de forma decrescente para a compensação dos estados pela desoneração das exportações, e de forma crescente para a equalização dos efeitos da reforma. 
Institucionais da Presidência da República, José Múcio Monteiro Filho; os presidentes do Congresso Nacional e da Câmara dos D eputados, senador Garibaldi Alves e deputado Arlindo Chinaglia; o relator da Comissão Especial da Reforma Tributária, deputado Sandro Mabel; o secretário de Política E conômica do Ministério da Fazenda, Bernard Appy; e o secretário da Receita Federal do Brasil, Jorge Rachid.

Paralelamente ao seminário, o Observatório da Eqüidade realizou duas oficinas: "Justiça Fiscal: Reforma Tributária e Distribuição de Riqueza", que teve como palestrante 0 presidente do Instituto de
Pesquisa Econômica Aplicada (Ipea), Márcio Pochmann, e "Indicadores de Qualidade do Sistema Tributário", quando foram discutidos os indicadores que 0 Conselho gostaria de acompanhar para avaliar os rumos da reforma e sua capacidade de alcançar efetivamente os objetivos de maior eqüidade fiscal.

O compromisso político assumido pelo Conselho de Desenvolvimento Econômico e Social configura um importante passo para se alcançar um pródigo horizonte social a partir de uma estratégica e progressiva rota de produção, eqüidade e justiça tributária. 